\title{
To-and-fro murmur in the young due to major congenital cardiac defects: is cardiac auscultation obsolete?
}

Keywords: Physical examination; diagnostic studies; congenital cardiac defect

Received: 18 June 2010; Accepted: 22 August 2010; First published online: 4 October 2010

Dear Sir,

Cardiac auscultation is becoming a dying clinical art. The balance between cardiac physical examination and imaging modalities in the diagnosis and delineation of congenital cardiac disease has changed significantly since the introduction of echocardiography, and more recently computed tomography, and magnetic resonance imaging, and is now leaning towards a mechanistic approach while the art of cardiac examination is losing its pivotal role.

To-and-fro murmur in the young emphasises the importance of cardiac auscultation. It comprises a lowpitched crescendo decrescendo systolic component and a decrescendo diastolic component with a short pause between the two, best heard at the mid-left parasternal border. Its presence indicates a major congenital cardiac defect and requires initiation of intensive cardiorespiratory monitoring in an intensive care unit setting as well as prompt diagnostic evaluation. The differential diagnosis must include the following major cardiac lesions: aortic-left ventricular tunnel ${ }^{1,2}$ (Fig 1), absent pulmonary valve syndrome ${ }^{3}$ (Fig 2), and truncus arteriosus with truncal valve incompetence (Fig 3). The aortic-left ventricular tunnel may be confused with other more common lesions as the coronary artery-left ventricle fistula and ruptured sinus of Valsalva ${ }^{4}$ (Fig 4). These lesions can occur in infants but have a diphasic murmur, often without the characteristic pause. The echocardiographic evaluation of children with coronary artery fistula reveals normal coronary artery anatomy. Both transthoracic and transoesophageal echocardiography reveal the aneurismal dilatation associated with the ruptured sinus of Valsalva, the site of rupture, and the length of the diverticulum. ${ }^{5,6}$ Ventricular septal defect with aortic regurgitation is associated with a to-and-fro murmur

Correspondence to: Dr A. Z. Gazit, MD, Divisions of Critical Care and Cardiology, Department of Pediatrics, Washington University, PO Box 8116, NWT/8th floor, One Children's Place, St Louis, Missouri 63110, United States of America. Tel: 314286 1246; Fax: 314361 0733; E-mail: gazit_a@kids. wustl.edu but is rare in young children. Echocardiographic evaluation of congenital absence of the pulmonary valve permits visualisation of the anterior misaligned ventricular septal defect with overriding aorta and a

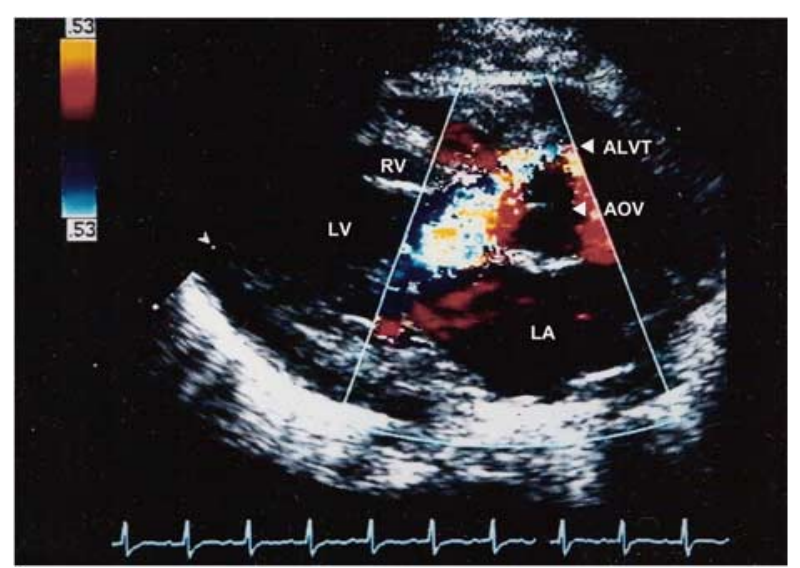

Figure 1.

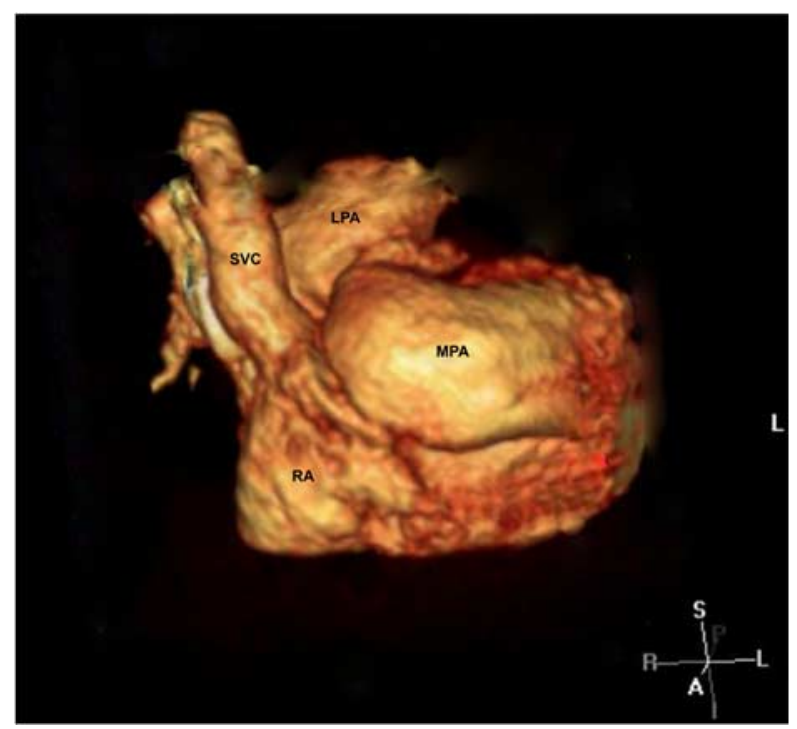

Figure 2. 


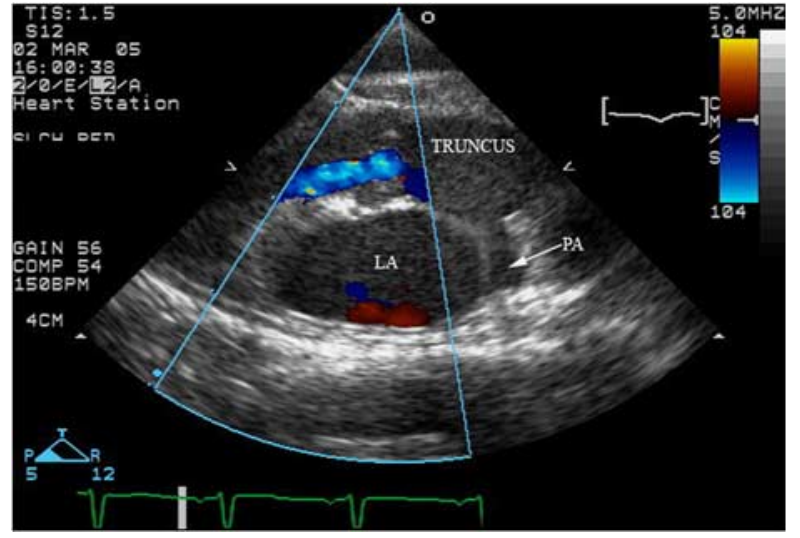

Figure 3 .

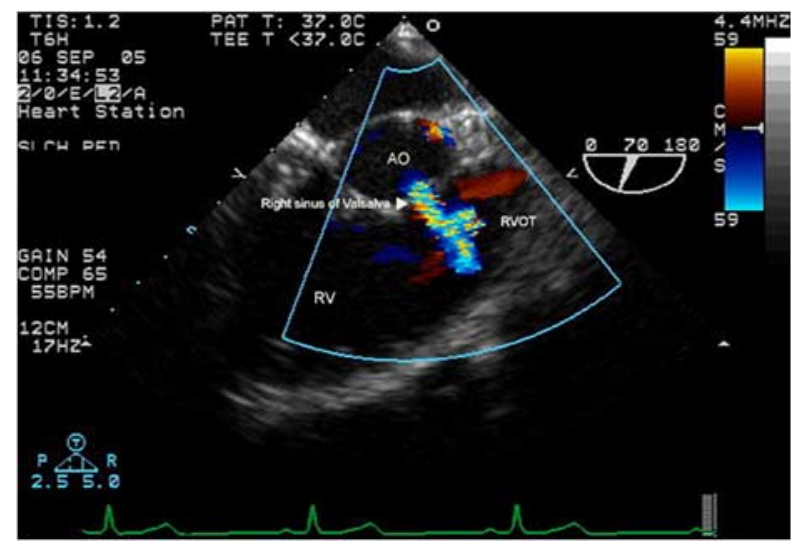

Figure 4 .

patent right ventricular outflow tract (in the parasternal short- and long-axis views). Delineation of the stenotic pulmonary valve annulus reveals in most cases an immobile rudimentary valve tissue. The characteristic aneurismal dilatation of the main and proximal branch pulmonary arteries may cause bronchomalacia due to external compression by the pulmonary arteries and may require plication at the time of reconstructive cardiac surgery. The third major cardiac lesion associated with to-and-fro murmur is truncus-arteriosus with incompetent truncal valve. ${ }^{7}$ Echocardiography discerns this conotruncal lesion as a constellation of malaligned ventricular septal defect, overriding aorta, absent right ventricular outflow tract, and a common trunk giving rise to both great arteries.
Doppler colour echocardiography shows the severity of stenosis and insufficiency of the truncal valve. Truncus arteriosus and aortopulmonary window are sometimes difficult to differentiate. The latter lesion is usually not associated with a ventricular septal defect, and the right ventricular outflow tract and pulmonary valve are usually in the expected position. Direct visualisation of an aortopulmonary window is possible using a high parasternal short-axis view.

In summary, it is not our intention to put down the importance of the state-of-the-art diagnostic modalities; however, gaining expertise in these techniques should not lead to the degeneration of our basic clinical capabilities. These continue to be a key component in planning the approach to the child with a congenital cardiac defect.

\section{Avibu Z. Gazit Divisions of Critical Care and Cardiology}

Gautam K. Singh, Mark C. Jobnson Division of Cardiology, Department of Pediatrics Washington University, St. Louis, Missouri United States of America

\section{References}

1. Jureidini SB, Nouri S, Kanter K. Aortico-right ventricular tunnel and critical pulmonary stenosis: diagnosis by two-dimensional and Doppler echocardiography and angiography. Pediatr Cardiol 1989; 10: 99-103.

2. Sreeram N, Walsh K. Aortic-ventricular tunnel in a neonate: diagnosis and management based on cross sectional and colour Doppler ultrasonography. Br Heart J 1991; 65: 161-162.

3. Sreeram N, Peart I. Fallot's tetralogy with absent pulmonary valve and anomalous origin of the left pulmonary artery. Int $\mathrm{J}$ Cardiol 1993; 42: 175-177.

4. Bonu M, Lakoumentas J, Brili S, Theoharis C, Aggeli , Harbis P. Echocardiographic diagnosis of ruptured aneurysm of the sinus of Valsalva. Echocardiography 2004; 21: 81-83.

5. Abdelkhirane C, Roudaut R, Dallochio M. Diagnosis of ruptured sinus of Valsalva aneurysms: potential value of transesophageal echocardiography. Echocardiography 1990; 7: 550-560.

6. Mathrene GP. Congenital anomalies of the coronary vessels and the aortic root. In: Allen HD, Gutgessel HP, Clark EB, Driscoll DJ (eds.). Moss and Adams' Heart Disease in Infants, Children, and Adolescents. Lippincott Williams \& Wilkins, Philadelphia, 2001, pp 675-688.

7. Mair DD, Edwards WD, Julsrud PR, Seward JB, Danielson GK, Goldmunz E. Truncus arteriosus. In: Allen HD, Gutgessel HP, Clark EB, Driscoll DJ (eds.). Moss and Adams' Heart Disease in Infants, Children, and Adolescents. Lippincott Williams \& Wilkins, Philadelphia, 2001, pp 910-923. 